\title{
Así que pasen treinta años
}

Codes BeldA, Guadalupe, El va y ven, Córdoba, Almuzara, 2016, 95 pp.

\author{
Artículo-Reseña \\ JAVIER TAFUR \\ Licenciado en Historia \\ Rafael Bonilla Cerezo \\ Università di Ferrara
}

\begin{abstract}
"Una rigurosa dieta de buena educación durante unos días hace milagros ¿̨verdad, don Fernando? No hay gorda que se resista, todas terminan volviéndose de lo más finas".

"Discúlpeme, soy consciente de que mi humor, el de los juristas me refiero, es difícil de entender".
\end{abstract}

Guadalupe Codes Belda

Albert Boadella dice de este libro que se acerca al teatro del absurdo y cita a Ionesco como probable precursor. Yo no soy crítico literario y mucho menos de la especie dramática. Así que no voy a rectificar al maestro. Pero sí me permito decir que Eugène Ionesco es mucho menos divertido que Guadalupe Codes. Y no digamos nada de Samuel Beckett, que entristecía incluso a su adusta madre, de la que aseguraba su hijo que era casi cuáquera. El teatro del absurdo, que pudiera ser rebautizado más convenientemente como "de la pretensión", tiene que ser escrito por españoles para poder ser digerido por personas normales, o sea, mentalmente sanas, es decir, razonablemente banales. ¿De verdad alguien ha leído Esperando a Godot o El rinoceronte (piezas, respectivamente, de Beckett y de Ionesco) con un mínimo de optimismo? Yo creo que no. Pero la gente suele confundir la seriedad con la inteligencia, sobre todo la que es más seria que inteligente. Por eso observaba Umbral que "lo que en Ionesco es talabar- 
tería y oficio, en Mihura es espontaneidad”. De hecho, también recordaba el genial columnista, de quien consideraba su "maestro trascendental, fundamental y cojo", que, al enterarse de que su oponente para su ingreso en la Real Academia era el general Díez Alegría, consideró fructuosa la oportunidad de dicho nombramiento "para enseńar a los académicos a decir PUM".

Escribió Ramón Gómez de la Serna — que las inventó- greguerías ingeniosas, e igualmente las escribe aquí Guadalupe Codes, que las ha recuperado para las letras actuales, pero difícilmente encontraremos una más sutil que la citada. Mihura fue un incomprendido con éxito. Tenía olfato para el teatro, para convencer al espectador de que el teatro solo merece la pena cuando se burla de uno; especialmente de uno. Tal vez para que no cupiese duda de que así lo hacía, puso un cartel en su teatro prohibiendo el paso a los novios de las actrices. Codes podría poner uno en el suyo invitando a las novias y novios de actores y actrices, no necesariamente en este orden, según lo políticamente correcto, para que completaran el elenco de esta pirandelliana obra, en la que resulta tan importante la descripción del escenario, sumada a la acción mímica del nutrido reparto, como su expresión oral. Lo de menos, a veces, es casi lo que dicen los personajes. Lo de más, lo que dice la autora de ellos y de su circunstancia. Ahí es donde el drama se llena de greguería, de doble sentido, de compromiso irónico, de metáfora y humorismo. Ahí es donde percibimos la extraña personalidad de Codes y su extraordinaria singularidad literaria. Decía Oscar Wilde, en los estertores del siglo XIX y en los suyos propios, que ya entonces era imposible ser original, "ni siquiera en el pecado". Nos viene ahora, empero, a demostrar Guadalupe, en los albores del siglo XXI, y en los suyos propios como escritora, que es posible ser original, incluso desatendiendo al pecado, como es lo natural en una católica practicante y profesora de Derecho y libertad religiosa.

Tal vez el problema de la literatura haya sido en este siglo largo pecar demasiado, adolecer de convicciones morales, relativizarlo todo hasta el hastío. Nuestra autora no cae en esa licencia. Su estilo no camina exento de provocación, pero es una provocación amable, piadosa, firmemente asentada en la creencia en un sentido trascendente de la humanidad, y no tanto en su devenir de ángel caído. Por eso esta obra tiene algo de auto sacramental. Y lo tiene no solo por su formato y por su gran simbolismo 
escénico, sino también por su condición pedagógica, por su voluntario carácter moralizador, porque en última instancia persigue y quiere afirmarse en un mensaje de fe y de esperanza. El reparto está formado por personajes alegóricos de la sociedad actual: la abuela —que además es taquillera - que fomenta la afición teatral y quiere recuperar al abuelo de su desidia; el nieto que parece haber dado un salto generacional hacia atrás para ser como la abuela; la pícara frutera, vistiéndose de frutas en una descripción digna del Cantar de los Cantares; el preso, que patéticamente es juez y más patéticamente aún desea ser político; el deportista que suda sin parar; el cura que es más papista que el Papa; el marido malasombra y vegetariano, que en el fondo, como todos los maridos malasombras y vegetarianos, añora la carne, el carnaval y ver a su mujer en Venecia, vestida de máscara, sobre una góndola que los lleve, al fin, al teatro; el anciano que ya no tiene edad porque es el último del geriátrico; la embarazada constante que acaba aceptando el confortable sudor del deportista...

Son individuos distinguibles, representan categorías en el teatro del mundo. No son actores, son personajes, preparados para interpretarse a sí mismos. Ramón — que solía abominar del teatro, pese a que escribiera diecisiete dramas - creía que éste debe mostrar "lo inexpresable unido a lo subconsciente", "libre de prejuicios que no sean el culto a la belleza"; o más allá de éste, añadiría luego. Lo suyo es el empeño "de desteatralizar el escenario, de intentar superarlo", de convertirlo en cosa ajena a las convenciones; acaso de despojarlo de lo estrictamente literario, de lo externo, al cabo, que subyace en el existencialismo y en el teatro del absurdo, para transformar la tramoya en el deseo mismo de devolver la experiencia teatral a su esencia prístina, a su naturaleza original, que es descubrir su propia mentira y, consecuentemente, la soledad genuina del hombre en el mundo; un deseo en el que, sin embargo, busca un significado último, distinto de la obra escrita, fuera de ella, en la intimidad del autor. En "su voluntariedad, su noche y su pipa”, llega a decir, con acomodado individualismo, Gómez de la Serna. Es lo que en El va y ven parecen expresar, en suma, el joven Federico y el tramoyista, ascendidos ambos en sus empleos. Porque la función debe continuar. Y si bien los personajes simulan al principio que todos esperan a Godot, es decir, un drama que nunca empieza, lo cierto es que nunca acaba.

Lo decía Jardiel: "Es inútil ponerse de espaldas a la sala, porque el es- 
cenario está enfrente". Jardiel respeta a la clientela; no la desprecia, pero tampoco la conmueve. En realidad, solo la epata, como burguesa habitual que es, sin que se dé demasiada cuenta. Por eso el madrileńo prefiere lo inverosímil a lo absurdo, para que la gente no se dé por aludida y se quede indiferente, que es lo que la gente cree, desde niña, que significa "inverosímil”, sin que sepamos muy bien el porqué. Indiferente, pero riéndose a mandíbula batiente, que es la forma de redención que la gente corriente enfrenta a la sorpresa y al pasmo.

Ramón, Jardiel, Mihura, sin olvidar a Edgar Neville, López Rubio o Tono. Estas son, supongo, las lecturas que han hecho posible el entremés moderno de Guadalupe Codes. Y llamo ahora "entremés” a su obra por la misma razón que tuve para llamarla antes "auto sacramental”. Porque, además del formato ligero y breve, añade al carácter alegórico el paródico; irradia humor, caricaturiza tipos populares y exagera perfiles sociales. Si empezamos hablando del absurdo al referirnos a su libro, ahora podríamos aludir al teatro clásico para explicar la fuente auténtica de su inspiración.

Guadalupe significa "río oculto". Y el agua naciente siempre ha estado unida al origen de las vírgenes madres, cuyas imágenes, perdidas y reencontradas una y otra vez cuando ha sido necesario, se asentaban en las oquedades de las peñas, solo a la vista de pastores predestinados. Del mismo modo, se diría que una línea de continuidad del drama de la humanidad, entre el moisés y la mecedora, viniese desde la noche del teatro hasta nuestros días, a través de claves escondidas en modelos aparentemente antagónicos, para dar a luz finalmente a la obra en la que la plenitud de los tiempos adquiere su sentido. No podía ser más feliz que durante el Adviento se haya presentado la delicada contribución que Codes ha hecho a esa obra eterna que es la Navidad, con sus Reyes Magos y sus villancicos, donde todos renacemos, con fe o sin ella, puesto que, en cualquier caso, volvemos a la infancia. "De niño, uno es feliz de verdad y, de mayor, pues... solo estira las sonrisas de aquella edad". Nos lo dice la autora llevándonos a un teatro, que es un sitio para soñar y para creer que, a la postre, otra vida es posible; más cercana a la inocencia, a la paz, aunque sea más onírica que real. Pero en ese ir y venir del sueño a la realidad y de la realidad al sueño tiene la literatura su tiempo y el teatro su espacio.

Por último, debo hacerles una confesión, que espero no se tome como 
burla, sino como licencia literaria. He escrito primero la presentación y luego he leído el libro. Me ha parecido la forma más digna de homenajear al teatro del absurdo, que con esta pieza — creo- alcanza, por fin, su madurez.

Ahora que de todo hace treinta años, puedo afirmar con pleno conocimiento de causa, y sin temor a equivocarme, que el bisabuelo de Federico en El va y ven dio en el clavo al explicarle a su hija la importancia de "no compartir el pupitre de la escuela con un capullo, por aquello de que a uno le podía terminar afectando" (p. 21). Gracias al Cielo, cuando echo la vista atrás, y confío en que mis compañeros de entonces - a los que frecuento- opinarán lo mismo, entre nosotros, florecidos o no, había cualquier cosa menos capullos. Tal vez porque dicha generación, y me remonto aquí a los párvulos que pisaron las aulas en 1984, efeméride orwelliana por excelencia, se toparían con ellos algo después: sumergidos ya dentro de ese otro ecosistema - tan abonado para el crecimiento de las plantas carnívoras - que atiende por "mercado laboral”, del que, ¡faltaría más!, no se libra ninguna de las universidades que en el mundo han sido.

Según les contaba - y me excuso por tamaña obertura, que acaso no sea "para en cámara"-, dentro de aquel grupo de niños que llegaron al colegio La Salle de Córdoba en plena Movida y con la bruja Avería por bandera (“¡Viva el mal, viva el capital!”) sobresalía uno muy rubio, muy alto, muy irónico y en posesión de unos raros — por desusados- modales que enseguida despertaron mi curiosidad. $Y$ es que, para qué negarlo, quien co-escribe estas líneas, como bien se sabe y han padecido los que trabajan conmigo (eufemismo de "a mis órdenes") o asisten a alguno de los cursos que suelo dictar a partir de las once de la mañana, se afana en - y se ufana de - no ser "ordinario"; o lo que sería aún más terrorífico, "normal". Se ufana, repito, porque junto a aquellos treinta y dos mozuelos y ocho lindas señoritas dignas de protagonizar alguna de las comedias de Jardiel — damas, en fin, que, al abrigo de la Mariana de Eloisa está debajo de un almendro, con el brillo de sus ojos nos revelaron "esa radiación inmaterial que despiden los seres excepcionales; [la elegante fosforescencia] de los espíritus singulares, [...] un poco fantásticos y siempre, y en todo 
caso, raramente selectos"-, acabé por aprenderme de pe a pa el himno de nuestro centro, cuyas estrofas más castrenses, y diría que salaces, encerraban una chistosa loa al humor absurdo. Sobre todo entonada por las canoras vocecitas de aquellas ocho niñas: "Joven, soy cordobés que se ufana / con su estirpe de egregios poetas, / pensadores, guerreros y ascetas / que ilustraron la patria y la fe. / [...] / Fiel a Cristo, prometo constante / conservar sin mancilla mi alma, / ostentando perenne la palma / de una fe convencida y viril".

iiiiii!!!!! Mis lectores serán muy dueños de rellenar aquí, haciendo gala de su más genérica libertad, las infinitas frases que podrían desfilar entre los signos de exclamación. Y una apostilla: imagino que en los tiempos que corren habrá sorprendido lo suyo el uso de un sustantivo tan sexista como "seńorita". Se lo dedico a todas aquellas que ni lo fueron, ni lo son, ni lo serán, probables socias compromisarias del club "Isabel monta a Fernando". Comprendan —ellos y ellas — que desde antiguo mi ideal lo vengo cifrando en la Palmira Suaretti de „Espérame en Siberia, vida mía!, que era lo que la gente llama una "mujer distinguida"; es decir, "una de esas mujeres que uno distingue muy de tarde en tarde".

Vuelvo a excusarme por desviarme del camino carretero... a sabiendas. Y es que tengo para mí que Laurence Sterne "erró con brújula” al declarar en su Tristram Shandy que las digresiones son como "el resplandor del sol; son la vida, el alma de la lectura”. Aquel muchacho rubio del que les hablo sentía además una gran devoción por el pueblo de Martos, sufrió la travesía del desierto del Atlético de Madrid — poco antes de que el presidente Gil amenazara al "Tren" Valencia (alias "El Negro") con acabar entre las fauces de su cocodrilito Furia- y resulta harto probable que — de nuevo como un servidor - pudiera dar la impresión, a todas luces frívola, de haber sido criado con biberón de leche de elefanta traída directamente de la India.

Sea o no cierto, lo peregrino del caso es que había recibido en la pila bautismal uno de esos nombres que marcan. Atendía - hoy como ayerpor Salvio Codes. No recuerdo bien si era el tercero o el cuarto de su familia que heredaba el patronímico del obispo y magistrado de Aquitania. Porque a nadie se le escapa que hay nombres, verbigracia Felisberto, Gumersindo, Recesvinto, Anirino, Ausentita o Urraca, que exigen cierta distinción a sus portadores. Y Salvio es otro que tal. Un par de paréntesis 
más tarde, los del bachillerato, la fumadora "Peña del Olivo", la facultad y las autopistas, esas migas esparcidas por un Pulgarcito que quisiera medirse con Gulliver, se las arreglaron para que en el 2016 - y hago mío otro título de Jardiel — yo piruetee a 400 kilómetros de Madrid y a 30 de mi amigo Codes: un abogado del bufete de Gómez Acebo — nomen est sanctus - que, como todo hijo de vecino desde que el mundo es mundo, o sea, desde que a Yahvé le dio por hacer una tournée para comprobar que no tenemos remedio, era también hijo de sus padres. Un matrimonio formado por la elegante Carmen Belda y por un inspector de Hacienda — se entenderá ahora mejor por qué el mozo les salió irónico- que lucía impecables trajes de raya diplomática y se parecía al William Powell de The Thin Man, pero sin el bigotito.

Pues bien, fruto de una charla con don José Luis Codes Anguita - a diferencia de los títulos nobiliarios, el don hay que ganárselo-y del afilado gusto de mi tía y hada madrina Carmen Cerezo, una tarde de primavera sin sueño, allá por 1991 —no me destetaron con leche de elefanta, pero sí que poseo memoria de paquidermo-, las figuras de Enrique Jardiel Poncela y el resto de los miembros de la Otra Generación del 27 entraron en mi vida para quedarse. Y eso que, antes siquiera de leerla, me empeñé en que la misteriosa Eloísa, a la que siempre he concebido como nuestra Rebeca patria, aunque sin el rictus que afeaba a la hermosa difunta del cuadro de la novela de Du Murier, filmada en hollywoodiense blanco y negro por Hitchcock, se encontraba sentada - y no yacente- debajo de un almendro.

Luego descubrí que Salvio tenía una hermana con ojos de mujer fatal: Guadalupe, querida colega en una Universidad andaluza de cuya sede no siempre quiero acordarme, italianizándola. Y que el refranero español y su propio hogar se habían encarnado en ella con agudísimo empaque. De casta le viene a esta galga, por lo que tampoco me extrańó que en el 2011 publicara junto a su progenitor el Derecho civil en versos (ed. Reus) y ahora vele armas como dramaturga con El va y ven, la comedia que tengo el gusto de analizar en collera con Javier Tafur. ¡Que Dios reparta suerte! ¡Valor y al toro! Y como se torea y se escribe como se es, no voy a negarle la mayor a Foxá cuando afirmaba que "el único músculo importante en el toreo - y en la filología, valga la licencia- es el corazón”.

Codes ha compuesto una opera prima inteligente. Demasiado inteli- 
gente para los públicos que corren (o chatean). Porque no ignora que la poética del teatro - y la del ruedo, según nos enseñó Bergamín en Mangas y capirotes y El arte de birlibirloque - consiste en desengañar al toro, perdón, a los espectadores; no en engañarlos. En saber burlarlos, pero sin burlarse de ellos. Y a fe que El va y ven lo hace. Una pieza, precisamente, donde la fe crece en aparcería con el humor. Sin embargo, quien entienda que ha tejido su texto como un hilo de Ariadna con el que coser sus greguerías, las mismas que la avecinan a los aforismos del JB del Cohete y la estrella. La cabeza a pájaros, o a los del Jardiel de Máximas minimas, andará tan desnortado como aquel pobre que falló que Cervantes había escrito El licenciado Vidriera solo para dar a la estampa una retahíla de facecias, chistes y citas latinas salidos de la boca de su protagonista.

Estoy convencido de que El va y ven, que podría haberse titulado El vaivén, o Él va, y ven, resucita, a su modo, una profecía de Ramón con la que, anticipándose al crack del 29, a la huidiza República y a la sombría Guerra Civil, que en nuestros días se han metamorfoseado en la Recesión del 2008, tan vivita y coleando, auguraba que "en este momento de transición, en que se ve lo que va a desaparecer y ya está de algún modo como desaparecido, y no se ve aún lo que aparecerá de nuevo en toda su rotundidad, el humorismo es el puente ideal". Voy incluso más lejos: la greguería, la máxima, el adagio, nada y nunca — mi aversión hacia las pompas de Steve Jobs y sus belcebúes no conoce límites - tienen ni tendrán que ver con un tuit. De hecho, son muy pocos quienes los cultivan en España. Y bastará citar las bajeras de las traseras de $A B C$ que firma el cineasta Rodrigo Cortés: "Verbolario", recopiladas como $A$ las tres son las dos (Salamanca, Delirio, 2013) y Dormir es de patos (Salamanca, Delirio, 2015), que beben lo suyo del afilado ingenio de Ambrose Bierce, del que la editorial Libros del zorro rojo rescató no hace mucho sus 99 fábulas fantásticas (2010) traducidas por Marcial Souto e ilustradas por Carlos Nine; y no me dejaré en el tintero esa joyita de la brevería que es No pasa nada si a mi no me pasa nada (2009), del poeta bejarano Luis Felipe Comendador, de nuevo auspiciada por los "delirios" de Fabio de la Flor. Les regalo tan solo una perla: "La libertad no existe para los que tenemos fincas". O bien: "Si decides enamorarte — ila encantadora Palmira Suaretti!_, hazlo de tu idea de mujer y no de otra cosa”.

Protagonizada por una comunidad de vecinos, El va y ven se mece 
como un homenaje al teatro y, asimismo, como una renuncia — tal vez renuencia- al genus naturalista, según razonaré más tarde. De ahí que todos los actores deban "gesticular de modo grotesco y excederse en la dicción". Estructurada en un solo acto dividido en seis cuadros, la autora no oculta en una de sus notas al pie que la mayor parte de sus diálogos se levantan sobre greguerías, de cepa burbujeante y barrica achampanada, que, en su caso, y con no poca sal, denomina "guadalerías". Un homenaje a Gómez de la Serna, por ser "imaginativo, rompedor, franco, entusiasta, surrealista, bienhumorado; [...] todo ello a un tiempo, y de modo ininterrumpido; [...] y a mí, las personas así, me caen muy simpáticas”.

No obstante, el lector se topa ya en el primer cuadro, y he aquí uno de los diminutos lunares - ¡cráteres de luna! - que puedo afearle a su texto - junto al estrambote que Codes añade tras la caída del telón, que juzgo baladí por rebajar la potencia de la elipsis entre el moisés y la mecedora, sobre la que volveré - con una cuestión tan resbaladiza como un cangrejo cocido; con un apuro, en suma, que se ha venido debatiendo desde los tiempos de Valle Inclán y luego de los de Jardiel: el carácter representativo o irrepresentable de sus acotaciones. En El va y ven el peligro se cifra -más que en las didascalias - en las notas-homenaje, casi una hoja de ruta, si no el mapa del tesoro, con las que Codes contrapuntea varias de sus escenas.

Sic rebus stantibus, nos hallamos ante un teatro para leer, o bien ante un teatro que precisaría de una voz en off, a modo de aparte, a zaga de las glosas infrapaginales de las novelas de Jardiel __iPero hubo alguna vez once mil vírgenes?-, no solo para explicar los guińos al crisol de dramaturgos por los que la autora siente devoción (el "teatro integral" de Shakespeare, Calderón, Lorca, Arthur Miller, Beckett, Muñoz Seca, Neville, Boadella...), sino para guardar como oro en paño las inspiradas guadalerías que el público nunca podrá saborear dentro de la sala. Un botón de muestra: "Siempre he tenido la impresión de que se puede adivinar mucha actividad cerebral tras una coliflor. Ello no obsta para que, del mismo modo, considere que hay quien, en lugar de cerebro, tiene una coliflor en la cabeza” (p. 16). Y no me privaré de copiar las más líricas y/o desopilantes: "Para gozo del verde, y la tranquilidad del "eurogrupo", los actores no fumarán durante la función. Albergo la ilusión de que no sea censurada mi primera obra. He puesto al cartel y al cenicero a rezar para contrarres- 
tar así, en parte, la ola secularizadora y de fanatismo impío que recorre España en la actualidad" (p. 16); "Gota de sudor... lágrima de la piel" (p. 22); "El de la trompeta es el único sonido que llega hasta las nubes, esos balcones que cuelgan del Cielo" (p. 46); "Los ancianos sois jóvenes multiplicados" (p. 68); “-¿La transversal ya no tiene funda que la proteja? -Ahora ya no. La tenía pero s(e) (h)A «ído»" (p. 44); "El yo-yo es el juguete que mejor sintetiza el egocentrismo infantil" (p. 50); "El sol solo dora a los ricos. A los demás, nos broncea modestamente" (p. 52); "En la cárcel dormimos la mitad que el común de los mortales, pero soñamos el doble" (p. 63); "Cada cigarro que se fuma un juez [...] es la vida de un condenado hecha ceniza” (p. 71).

Puesto que he aludido ya a los guiños, no estará de más abundar en el decorado que preside la obertura de El va y ven: "Un hermoso ojo con enormes párpados y largas pestańas; se cerrará, [...] [como digo], cada vez que la autora pretenda destacar la influencia de algún escritor, filósofo o dramaturgo. [...] Al fondo, un columpio recorrerá el espacio escénico de izquierda a derecha [y viceversa] mientras dure la función; dentro del columpio hay otro ojo, que permanecerá cerrado durante toda la obra, a modo de guiño permanente" (p. 13). He aquí mi cómplice reproche a Codes, que, con admirable modestia, precisa que "para qué vamos a engañarnos, no hay muchos guiños”. Y me pregunto: ¿no les ha venido a la memoria el onírico techo poblado de ojos que Dalí diseñó para Spellbound (Recuerda, 1945)? ¿Y no tendrá algo en común ese ojo de El va y ven con el Big Brother de Orwell, y hasta con los que escrutaban a la bailarina en el cortometraje (Destino) que el propio Dalí y Walt Disney animaron al alimón hacia 1945? Respecto al globo ocular cerrado que se cimbrea de acá para allá, les invito a echar un vistazo — ¡qué si no!- — a las fotos en 3D del turinés Fabio Berti y al poema Idea (2015) de Francisco Aliseda. Y conste que he citado por dos veces al genial pintor de Figueras porque no ignoro que, en el segundo cuadro, la lámpara de la consulta del médico tiene forma de chupete (p. 26).

Lo escribí antes, y lo repito: el muro con el que tropezará la pieza de Guadalupe Codes es la falta de un público dotado de los saberes que ella — culta como es_ l le demanda. Por eso yo hubiera prescindido del susodicho par de ojos, más o menos dalinianos, más o menos quevedianos, dejando los homenajes más ocultos, más esotéricos, si se quiere, para 
obligar a quien asista a su espectáculo a descubrirlos a calzón quitado. Asumamos lo archisabido, que en la pluma de Bergamín solía adoptar el martilleo de una salmodia: "Bienaventurados los que no saben leer ni escribir, porque ellos serán llamados analfabetos”. Diríase que para Codes el teatro será calderoniano, más que lopista, o no será. Con otras palabras: si solo el vulgo pagara el billete de esta comedia — donde por cierto ningún sujeto viste esmoquin ni de blanco satén-, su autora se negaría a hablarle en necio; y con mucho gusto.

Dos actantes del primer cuadro (el director y el tramoyista Ignacio) ofician como maestros de ceremonias; son un par de obreros chambelanes que nos anuncian que la comedia de la vida va a comenzar, igual que en el clásico (Twentieth Century, 1934) de Howard Hawks. A continuación, nos deleitamos con un escenario de tres alturas, demediadas por varias puertas — hay que aplaudirle a Guadalupe su talento para la carpintería teatral - que dan entrada a una casa que alberga, según ha seńalado Tafur, una frutería, un gimnasio, una iglesia, la consulta de un ginecólogo, un parlamento, un geriátrico $y$, por último, un bar. Todas las puertas pertenecen a esta comunidad y, claro, como cabría suponer, se hallan en los antípodas de otras que los menos avisados juzgarán similares y que, empero, hunden sus mediocres jambas en la tiranía de los mass media: las de las risas enlatadas, o pequeñoburguesas, o amojamadas, esto es, amortajadas. Creo que nadie me rebatirá a estas alturas que el productor José Luis Moreno (o quizá el cáustico Rockefeller, su mejor creación, si es que no fue al contrario) hace tiempo que se vendió a las hieles del pan y del circo.

Ustedes me entienden: la comunidad del señor Cuesta y el resto de los que se nos avecinan. Por el contrario, el bloque que ha construido Codes acarrea bastantes más ladrillos de 13 Rue del Percebe, que Ibáñez dibujó para la revista Tío Vivo en 1961, y sospecho que de la no tan popular Una casa en Nochebuena, salida de los lápices de Xaudaró, quien acostumbraba a firmar sus tiras con un chihuahua blanco. Un auténtico punto filipino, habida cuenta de que este viñetista nació en aquella excolonia española. Pero el patio de vecinos de El va y ven también conserva algún que otro baldosín de la pirandelliana pensión por la que pululaba el paisanaje de Alberto (1949), la primera obra que José López Rubio estrenó en solitario. Y no podía faltar en mi reseña la "habitación de un hotel de segundo or- 
den", abierto en una "capital de provincia de segundo orden", de los Tres sombreros de copa (1932) de Mihura: una comedia que es prima segunda (aunque tres años mayor) del camarote que superpoblaron los hermanos Marx en $A$ Night at the Opera (Sam Wood, 1935), toda vez que el madrileño se encargó de traducir al espańol durante la década de los Treinta muchos de los diálogos de las cintas de Groucho, Harpo, Zeppo y Chico. Y por ello, desde la ya mítica Duck Soup (Sopa de ganso, Leo McCarey, 1933), las correrías de Rufus T. Firefly (Groucho Marx), que llegaría a ocupar la presidencia de Libertonia, nos resultan — si cabe- todavía más descacharrantes. Bien es cierto que Córdoba no es cualquier lugar de Europa, ni muchísimo menos de Libertonia; y, aunque me duela —Pemán destiló aquí la lejía de sus sarcasmos—, también lo es que "casi nunca ha dejado de ser un vagón de primera con gente de tercera”.

Desde el principio, Codes se las maravilla para cargar la ironía de sus tintas felices, pues no conviene pasar por alto que los parroquianos del inmueble son los esperables, con excepción de dos: el parlamento, donde entrará un preso que antes había ejercido como juez (¿sobrevuela por aquí la sombra del magistrado estrella (y estrellado) Baltasar Garzón?); y el bar, convertido en el conspicuo reino de un malasombra. Ańado otro detalle capital: en este circo de tres pistas y alturas, en esta suerte de corral de comedias de vanguardia, la autora ha incluido un balcón andaluz en el que se lee "Teatro" y al que se dirigen todos y cada uno de los miembros de su bizarra "Asociación de ideas". Una politeia, muy aristotélica por cierto, que fiará su destino a la balanza de la "autarquía".

El segundo cuadro nos sitúa frente a una cola $-y$ algún rastro queda de lo que en nuestro Barroco se conoció como "entremés de figuras", cuyo rescate emprendió don Eugenio Asensio- a la que se irán sumando los variopintos personajes de Codes, que desean asistir a una función de la que nada sabremos. Y lo hacen al son de la Carmen de Bizet, porque, según aclara la autora en sus notas de polvo de estrella, "no es habitual que un francés acepte gustoso que su obra esté ambientada en España (¡nada menos que en Sevilla!); porque uno de los personajes es torero, [...] y finalmente porque el autor fue un auténtico visionario de los nombres tan horteras que los españoles elegirían para sus hijas más de un siglo después. [...] También he de confesarles que mi madre y mi hija pequeña se llaman Carmen, pero esto no tiene nada que ver" (p. 19). Llegados a 
este punto, no me resisto a deslizar un apunte de hispanista de provincias con vocación de servicio público: no dejen de leer el ensayo sobre este particular que Jean Canavaggio acaba de publicar en el Centro de Estudios Europeos: Las Españas de Mérimée (2016), quien -como el autor de dicha monografía, aunque esto se diga menos de lo debido- fue un atento estudioso de Cervantes y los clásicos de nuestro país.

Es entonces cuando la abuela de Federico nos avisa de que lo que se representará dentro de la sala —o tal vez fuera, porque no desvelaré al lector (ni a la lectora) la última vuelta de tuerca del texto de Guadalupe Codes, en la mejor tradición de Pirandello o de Brecht_-, la tierra prometida que nosotros nunca pisaremos, o quizá sí, es una "obra de teatro sobre el amor al teatro" (p. 21). Tanto como hayan podido serlo, respecto al cine, La nuit americaine (1973), de François Truffaut, o la vilipendiada — por incomprendida - La reina de España (2016), de Fernando Trueba, secuela de la en principio sí meritoria La niña de tus ojos (1998). Las tres poseen un vínculo en común y Codes lo declara sin ambages: "los que llevamos dentro [el teatro o bien una pantalla plateada de sombras] observamos la vida con otros ojos. ¿Puede haber algo más ilusionante?”.

No deberían escapar al lector atento una serie de detalles de este segundo cuadro; como esa frutera que abre una granada por la mitad y saca de ella una pulsera de rubíes: metáfora digna de los bodegones poéticos del tiempo de los Austrias, con el zurrón de Polifemo, las Soledades de Góngora o los versos de Chiabrera a la cabeza. O esa acotación en la que la misma frutera adorna su cuello con un racimo de uvas verdes $-\mathrm{y}$ nada agraces, por llamar a capítulo a las moras de Carmen Jodra- y nos devuelve un retrato de vanguardia en la encrucijada que anuda el Cantar de los Cantares — así lo ha glosado Tafur - con los cuadros de Hermenegildo Anglada Camarasa o Maruja Mallo — remito a su Racimo de uvas con forma de corazón y al no menos sugerente La sorpresa del trigo- y la samba de una tercera Carmen, de apellido Miranda, ya que la frutera de Codes se toca con una piña en el pelo.

Y qué decir del deportista que llega raudo y sudoroso a la misma cola y a la misma taquilla de ese teatro que «vemos pero no vemos» en "calzoncillos a lo Cary Grant” (p. 23), el indiscutido rey de la screwball comedy de la RKO y la Metro. Obviamente la dramaturga nos incita a pensar en una de las secuencias más celebradas de North by Nortwest (Con la 
muerte en los talones, 1959), otra vez del maestro Hitchcock; o en el albornoz que le servía a Grant como abrigo en Bringing up, baby! (La fiera de mi niña, Howard Hawks, 1938). De todo ello les ofrecerá puntual información el delicioso artículo —a los filmes protagonizados por el de Bristol se les ajusta mejor que al resto, como un guante cibelino, el epíteto "delicioso" - colgado el 9 de noviembre de 2012 en el blog Donna mi prega: https:/guidocavalcanti.blogspot.com.es/2012/11/cary-grant-encalzoncillos.html.

A su lado - quiero decir al lado del sportman, no de los calzones de Cary Grant: somos gente fina-, Guadalupe Codes sitúa una peculiarísima iglesia con una centralita para atender comuniones, bodas - excluyendo las de oro, hoy día convertidas en raro desiderátum- y funerales; la diócesis de un cura al que Dios en persona, o en espíritu y voice over, como en la novela de Jardiel o en las películas de Frank Capra (It's a Wonderful Life!, ;Qué bello es vivir!, 1946), del que vitoreamos su 120 aniversario, y más tarde en las de Berlanga (Los jueves milagro, 1957), no dudará en sermonear si lo juzga preciso. Pocos filmes tan navideños y heideggerianos - la reflexión sobre el tiempo y el ser más sugestiva que yo haya visto - como el de Capra, cuyo sello sobre El va y ven juzgo categórico en este segundo cuadro. Basta fijarse en la escena de la embarazada a la que entregan una ecografía tridimensional que le permite contemplar el pasado, el presente y el futuro; y al ginecólogo que enfrenta a la madre con la imagen de su hijo algunos años después. Téngase en cuenta que la profesora Codes cree a pies juntillas en Melchor, Gaspar y Baltasar. Lo mismo que yo fabulo a menudo con Clarence (Henry Travers), aquel Sancho Panza del Cielo que vino a la Tierra para escudar y salvar la vida de George Bailey (James Stewart) en la villa de Bedford Falls (o Potterville).

Como digo, la obra de Guadalupe Codes es incisiva, pero salerosa y valiente. Y cuando se es valiente, suele haberse conocido la verdad, de tal modo que esa misma verdad nos haya hecho un poquito más libres. Por eso se atreve, dentro del segundo cuadro, con saetas de incorrecta política - parto de la evidencia de que la política (y el político) hace mucho que abandonaron lo correcto-, como esa acotación en la que un rebaño de ovejas cruza la escena y se oye un sonoro "beeeeee" justo después de una nota (p. 27) en la que la autora ha escrito: "Me gustaría poner de mani- 
fiesto la incertidumbre que me provoca el voto de confianza que nuestro papá Estado — ay, si me adoptara alguien! — nos otorga en la actualidad. Seguramente movido por la noble diligencia propia del buen padre de familia, tiene mucho gusto en hacernos partícipes, a todos sus hijos, de los momentos más importantes de la vida, como supongo que es el de depositar nuestros votos en una urna; y ello, con independencia de que tengamos - $\mathrm{O}$ no- alguna noción sobre economía, relaciones internacionales, sanidad, seguridad interior, educación... y qué sé yo".

Se comparta o no su postura, porque para gustos los colores y los votos (azul, rojo, naranja, verde y hasta violetas en el ojal), Codes, que parecería alistarse aquí del lado del preliberalismo ilustrado, herencia de Montesquieu, también armoniza (joh sorpresa!) con el recientemente fallecido Gustavo Bueno, padre del materialismo filosófico, quien, antes de pasar a mejor vida, concluyó que "habló el pueblo y dijo... mu". Para ser exactos, dedujo que "en Espańa cada uno dice lo que le da la gana y no sabe lo que dice". Ergo cabe inferir que nuestra piel de toro siempre se ha resistido a abjurar de su carpetovetónica dehesa de gran teatro del mundo (absurdo).

Puede provocar algún sarpullido — se les curará enseguida - que la frutera, en su diálogo con el "deportista en general", le replique que "si fueses un deportista de género, te tendríamos que llamar deportisto, ¿verdad?" (p. 27) y se cebe con una asignatura tan inútil como la "transversal de género", materia que, sin ninguna duda, les podrá ilustrar mejor que yo cualquiera de los que poseen una coliflor en lugar de cerebro. Acaso porque, como intuye Codes, "en el Syllabus del siglo XXI" la sílaba prohibida no es otra sino "ta"; la misma, de hecho, que repelía al abuelo Vanderhof (Lionel Barrymore) de You Can't Take It With You (Vive como quieras, Frank Capra, 1938), quien — mutatis mutandis - no comulgaba con ningún movimiento, ideología o quehacer que pudiera etiquetarse por medio del sufijo "-ista".

También se antoja un punto espinoso el diálogo —y la toma de partido- entre la frutera y el cura acerca de cómo debería actuar este último en el amargo trance de darle la extremaunción a una embarazada, siempre que se asuma que "toda vida humana tiene alma" (p. 53). El clérigo opone entonces que se vería en la obligación de consultar el Código de Derecho Canónico. No da puntada sin hilo Codes, quien desliza a lo largo de su obra varios guiños al Papa Francisco; el mismo que ha alentado claras 
“indicaciones de austeridad” (p. 46), dando así al traste, a mi juicio, con el viscontiniano trousseau de Benedicto XVI, cuya ciencia estética - verbigracia su camauro, el gorro de terciopelo escarlata forrado de armiñoabrigaba toda una declaración de principios éticos que abogaban por los ritos preconciliares y hasta diría que por la existencia de un Dios al que debe de complacerle la hidalguía y principalidad de sus ministros. Si así lo quiere Bergoglio, que apuesta en cambio por volver a "los modos de las primeras comunidades cristianas" (p. 48), me sorprende que Codes -que enuncia cristalina su postura al hilo de los embarazos de alquiler: "Los hijos, al fin y al cabo, son una madre dividida... Y dividirse por otra, caray, ya hay que ser mema” (p. 55) — no se haya mojado aquí siquiera en una de sus notas; sobre todo porque desde hace un par de siglos contamos con el Tratado de embriología sagrada (1848) del padre Inocencio María Riesco Le-Grand (II, IV, 5) y el propio Francisco acaba de bautizar al hijo de una madre soltera y a otro fruto de un matrimonio civil; amén de que la Comisión Teológica Internacional se pronunció con firmeza en el 2007 sobre dicho particular: "La esperanza de salvación para los niños que mueren sin bautismo”. Fin de este pequeńo sermón, en la medida que no tengo ni un pelo de teólogo. Eso sí, el cura de El va y ven - y conste que servidor ha tratado con más de uno, y de dos, que no podían pasar sin su contorno de ojos - seguro que lucirá (o debería hacerlo) alzacuellos y clergyman de seda, ya que “¡a ver cuándo dijo Jesucristo que los curas y los religiosos no puedan amar el arte y la cultura!” (p. 62).

Dejemos a la embarazada — y al Papa Francisco — tranquilos, para que el foco ilumine ahora al preso que entra en su "casa" tarareando el himno del Atleti. El maleante responde por Melchor y acaban de concederle el tercer grado. Enseguida toma la escena un lúcido viejecito que, como el Carl Fredricksen de Up! (Pete Docter, 2009) o El abuelo que saltó por la ventana y se largó, de Jonas Jonasson (Salamandra, 2012), detesta juntarse con los de su quinta, ansía celebrar su cumpleaños en un teatro y opina, cual Unamuno redivivo, que lo mejor sería volver "a la edad aquella en que vivir es soñar". Una técnica, esta de las citas citables, que vincula a Guadalupe Codes con el teatro de Bertold Brecht y hasta con lo que Azorín tituló "sinfronismo", o sea, la coincidencia de sensibilidad, pensamiento y estilo con los novelistas, dramaturgos y cineastas objeto de sus lecturas. 
Más a contrapelo discurre su defensa a ultranza del tabaco, esa "pasión de la gente cultivada, [hasta el punto de que] el que vive sin tabaco no es digno de vivir" (p. 72). Y vaya en mi descargo que un servidor no ha fumado un cigarro en su vida. Por eso he tenido que pedir cierta indulgencia plenaria a la autora y a muchos de los miembros de mi familia para, al menos, sobrevivir mal que bien.

No me he olvidado del malasombra apostado en el bar. Tiene sed, pero no sabe de qué. Si continúa sobrio, luego le haremos una visita. Adelanto apenas que el sacerdote no tarda en invitarlo a que frecuente su bloque —entiendo que católico_- donde podrá encontrar la felicidad y, con ella, la locura (p. 58). Siempre que no sean lo mismo, como propuso el utópico Don Quijote: el deseo del bien y la derrota del mal; el desrazonamiento del sentido común en aras de la verdad, de la virtud y de la belleza.

El tercer cuadro representa uno de los aciertos de esta obra. La autora indica que las figuras de su entremés "se convierten en muńecos de tela -o marionetas_-, quedando en estado «latente», salvo cuando comience a intervenir cada uno de ellos: en ese momento «recobrará vida» y se pondrá de pie para volver a sentarse” (p. 35). Estoy seguro de que, tratándose de una entusiasta del universo lorquiano, tan certero quiebro participa de los primeros tanteos escénicos del Grupo del 27, con el granadino y Alberti abriendo el cartel. No debería ignorarse la fortuna del teatro de títeres durante los locuelos años Veinte. Piezas como El maleficio de la mariposa (1920), con un reparto formado por curianitos y gusanos, o la farsa del Amor de Don Perlimplín con Belisa en su jardín (1933), nunca hubieran sido los mismos de no haber rodado por Europa a lo largo de esa década la compañía de títeres del Teatro dei Piccoli del italiano Podrecca, retablista y taumaturgo italiano, creador de un "teatro de los prodigios" - tanto como lo es El va y ven-. No en balde, contribuyó a la reteatralización de la escena de Vanguardia con fábulas y operetas acunadas por una ola de novedad comparable, según razonó García-Abad, a la de los ballets rusos de Diaghilev. Un Grand Guignol, en definitiva, que pondría la primera piedra para compañías tan modernas como Títeres Etcétera.

Pero no nos engañemos. Las figuras de El va y ven casi nada deben a los cristobitas ni a los autómatas de cachiporra. Tampoco a los puppi sicilianos de los Hermanos Napoli. No sienten el menor deseo de aburrirse, 
ni de contarnos miserias en el portal de ninguna escalera. Son parientes lejanos del baile de máscaras ideado por Castelao para Os vellos non deben de namorarse (1941) y, más aún, de la tesis del actor como "supermarioneta” (über-marionette), en el haber de Gordon Craig. Codes nos brinda un teatro simbólico en el que, partiendo del envite wagneriano del "arte total”, el entorno dramático no rodea, sino que justifica el estado anímico de unos sujetos con altos vuelos de sainete — porque España, independentistas incluidos, se ha trocado en un cuadro de (malas) costumbres a lo Arniches_- sin rozar apenas la astracanada ni el vodevil. Pero no del Arniches - lo matizaré_- que confiaba en "estimular las condiciones generosas del pueblo y hacerles odiosos los malos instintos". La autora se apoya, aun con cuentagotas, en varios recursos antirrealistas (los ojos que presiden el escenario) para encuadrar la mirada del público. Y vuelve a dar en la diana - huyendo de lo fácil — al no convertir su auto sacramental, su sainete, su entremés de figuras, en una jaula de grillos. Y eso que el malasombra exclamará atónito: "Madre mía, ¡pero si están todos pirados!” (p. 49). Sin embargo, tal y como ocurría en la Eloisa de Jardiel — salvo Micaela - , ninguno de estos personajes es un trastornado, ni un bala perdida. Sí que lo son, para decirlo con Ortega, las circunstancias que los acechan.

No tiene desperdicio la charla entre el malasombra y el preso (p. 63) acerca del traslado de la cárcel al extrarradio; de ahí la conversión del segundo en un "excéntrico" de cuidado antes de su vuelta a casa y, en buena lógica, de "re-centrarse". Más que hilarante, y no falto de doblez político, el que Codes ponga justo en la boca del preso una de sus greguerías más preclaras: "La libertad radical hace tanto daño como los radicales libres" (p. 64).

La obra acaba dando entrada al anciano Alberto, al que la frutera define como como "la nuez de nuestro bloque" (p. 68). A mi juicio, se trata del vecino que fija la clave interpretativa de toda la pieza cuando alude a que el malasombra sufrió la muerte de un hijo. De hecho, nos informa de que la mujer de este malaje fue la única que logró rescatarlo de la depresión en la que estaba sumido con un sonoro recreo: la orquesta en la que el sieso en cuestión toca el contrabajo. Y eso es exactamente El va y ven, una orquesta afinadísima en la que cada uno de los vecinos acompaña, a semejanza de las barcarolas para gondolero y coro, cuyo ritmo se basa 
en el movimiento de los remos, al que lo antecede y lo sigue en la cola frente a la taquilla. La orquesta, y más aún sus greguerías, que acaban por transformarse en la lengua franca del bloque, aunque a algunos le sonará a esperanto, es la tabla de salvación a la que se agarra el atribulado Malasombra, a la sazón marido de Rocío, que hace aquí las veces de taquillera. Por eso el gris contrabajista que solía gastar sus días y sus noches acodado en la barra del bar, como los mohínos perdedores de los lienzos de Hopper, empieza en el tercer cuadro, y solo en el tercero, a disparar - engarzándolas en rosario- nuevas guadalerías.

En resumidas cuentas, al final de cuarto cuadro, este Malasombra oficia ya como el "mejor embajador del gran teatro de mundo" (p. 78). Y su evolución trae de nuevo a mi memoria el New Deal de Roosevelt y Frank Capra, las luces de los seres humanos cuando alcanzan a engolfarse de "caoherencia", lujosamente obumbrados por el tisú y las lentejuelas de las comedias chifladas de Mihura, Jardiel o Neville, pero también de las de Lubitsch, Hawks, La Cava, McCarey, Leissen o Sturgess.

Incluso revolotea por esta comunidad de Codes, bastante más amable y menos corrosiva que la de Álex de la Iglesia (2000), esa curiosa Familia (1996) de Fernando León de Aranoa, cuyo debut en la pantalla grande se colocó seis peldaños por encima de lo que nos ha ofrecido después. Insisto: la "orquesta” es la clave; porque también la abuela Rocío se encarga de orquestar la farsa que me he resistido a desvelar y que tiene que ver lo suyo con romper la cuarta pared, pero hacia dentro del escenario. $\mathrm{O}$ si se quiere, la culpable de procurar que nadie sepa $-\mathrm{y}$ su marido menos que nadie - que las cosas nunca son lo que ni cómo parecen. La directora de un sainete — no me olvido del papel simbólico de la embarazada: por eso reciclaré el verbo "gestar" —, de "una familia sin parentesco» y hasta de una especie de gangarilla o compañía de cómicos de siete lenguas que se repliega sobre sí misma y debiera ser declarada de protección oficial. Porque ese bloque demediado al que me refería al principio de estas líneas encarna la clave de bóveda, la genuina protagonista de la pieza de Codes; igual que lo había sido la casa-fortín de Carrizales en El celoso extremeño de Cervantes. Ese bloque autárquico en el que "todos [sus] miembros nacen, crecen, se divierten, se reproducen y mueren; y todo eso, sin necesidad de salir de alli’”, simboliza el espejo invertido de cualquier totalitarismo de gris o rojizo pelaje; un oasis donde la vida, que rara vez responde 
a nuestros anhelos, por más que sepa arreglárselas para confortarnos con fotogramas que sí coquetean con lo sońado, cobra su pleno sentido al disfrazarse de quimera, de pantomima y de gozoso carnaval.

En el quinto cuadro asoma el segundo giro argumental de El va y ven. Lo que podría haberse reducido a un mero epígono de comedias negruzcas del jaez de Death at the Funeral (Un funeral de muerte, Frank Oz, 2007), termina evolucionando hacia una estructura con dos tramas en paralelo, pero sin superposición - la taquillera y el tramoyista, por un lado, y la cola delante del teatro, por el otro- que confirman la audaz propuesta de Guadalupe Codes, que parece heredera de los diálogos multitudinarios de Jardiel o, más si cabe, de los planos secuencia de García Berlanga.

El broche donde se dan la mano un bautizo y un réquiem, lindero de esos cuentos de Navidad pesadillesca con alguna caricia dickensiana, vincula El va y ven - por varios motivos en los que no puedo detenerme aquí- con La primera noche de mi vida (1998) de Miguel Albaladejo. El entremés vuelve entonces a recogerse sobre sí mismo, elevando su ironía al cuadrado, con sones de comparsa, porque ahora nadie es lo que dijo ser; y si nadie era lo que había dicho, se me antoja lícito que — como el mismísimo Don Quijote- cada cual se instale en la ficción, la orqueste, la dirija y la protagonice donde, tal y como le venga en gana.

Ese bautizo y ese entierro que cierran la pieza son la proyección del moisés y de la mecedora que se hace astillas al final; una imagen felicísima, por elíptica, del ciclo de la vida (o tal vez del eterno retorno); un epílogo afligido pero esperanzado, errabundo pero inmóvil, como lo era aquella otra mecedora desde la que Mose Harper (Hank Worden) avistaba y esperaba, con un lapso de varios meses y dos horas de metraje, la ida y el regreso de Ethan Edwards (John Wayne) en The Searchers (Centauros del desierto, John Ford, 1956).

Obviamente, el texto de Codes, que sabe cómo convertir la carcajada en humor sonrisa, nada tiene que ver con un western. Eso sí, creo que ese plano de la obra maestra de Ford, que se abre con una puerta y se cierra con otra, del mismo modo que El va y ven se abre con un ojo que acabará por cerrarse, se arrima por varios de sus flancos al sacerdote-guerrero "Le Capitaine" que encarnó Ward Bond, cubierto por una improbable chistera en medio de los roquedales de Texas; y sobre todo, al tronado y me- 
siánico Harper, que solo pedía un techo, una mecedora y un fuego junto al que calentarse. Igual que el anciano que se balancea en la despedida de esta pieza, sin que llegue a tomar la palabra en ningún caso. El mismo que — así quiero imaginarlo_- en siglos más civilizados, recordó que de niño poseyó un mundo que valía de veras la pena. El capitán de una infancia con aposentos de jardín, de películas, de circo... y de manicomio. 